Contents available at: Sri Lanka Journals Online

\title{
An Evaluation of Semen Quality of Donor Bulls in the Central Artificial Insemination Station (CAIS), Kundasale, Sri Lanka
}

\author{
W.W. Abeygunawardana1, P.G.A Pushpakumara2, H.M.S Wasana2, W.M.T.D Rathnakumara ${ }^{2}$ and B. \\ Alexander $^{2 *}$ \\ ${ }^{1}$ Department of Animal Production and Health, Gatambe, Sri Lanka. \\ 2Department of Farm Animal Production and Health, Faculty of Veterinary Medicine \& Animal Science, University of \\ Peradeniya, Peradeniya, 20400, Sri Lanka
}

\section{ARTICLE INFO}

\section{Article history:}

Received: 08 August 2020

Revised version received: 27 July 2021

Accepted: 09 August 2021

Available online: 01 October 2021

\section{Keywords:}

Animal breeding

Bulls

Fertility

Milk production

Semen quality

\section{Citation:}

Abeygunawardana, W.W., Pushpakumara, P.G.A., Wasana, H.M.S., Rathnakumara, W.M.T.D. and Alexander, B. (2021). An evaluation of semen quality of donor bulls in the Central Artificial Insemination Station (CAIS), Kundasale, Sri Lanka. Tropical Agricultural Research, 32(4): 426-433

DOI: http://doi.org/10.4038/tar.v32i4.8511

Abeygunawardana, W.W.

https://orcid.org/0000-0003-0835-1641

\section{ABSTRACT}

Fertility assessment of semen donor bulls used in Artificial Insemination programs is an important step in improving dairy industry in Sri Lanka. A study was conducted to evaluate the fertility of semen donor bulls using semen parameters and respective pregnancy rates. The semen donor bulls $(n=21)$ in the Central Artificial Inseminations Station, Kundasale were selected for the study, and the hypo-osmotic swelling test was performed for both fresh and frozen semen of each bull. Data were analysed using statistical function of Excel software version 2010. Presence of high percentage of hypo-osmotic swelling positive spermatozoa in both fresh and post-thawed frozen semen indicated that all bulls studied were highly fertile. A total of 49255 AIs has been performed in four provinces with an overall pregnancy rate of $28.2 \%$. The highest pregnancy rate of $57.6 \%$ was recorded in the Northern Province and the lowest pregnancy rate of $22.5 \%$ was recorded in the Central Province. The study revealed that there was no significant difference $(p>0.05)$ in semen quality among individual bulls or among breeds. Although the semen quality of the bulls was in the acceptable range, the pregnancy rate differed significantly $(p<0.05)$ according to the area. In addition, the overall pregnancy rate was (28.2\%) below the acceptable level. Further studies are required to investigate factors associated with semen quality and the low pregnancy rates observed in some of the areas.

\footnotetext{
* Corresponding author: pabda@pdn.ac.lk
} 


\section{INTRODUCTION}

Artificial insemination (AI) was first introduced to Sri Lanka in 1938 (Mahamooth, 1955). At the beginning, it was limited to private breeders and then expanded to the field level in 1951 using chilled semen (Mahamooth, 1955; Jeganathan, 1955). The Deep-Frozen (DF) semen technology was introduced to the country on an experimental basis in 1966 and the field application of it was initiated in 1968 (Jainudeen, 1968). The number of AIs per annum increased from 72 in 1951 to 108,338 in 1996 over 45 years (Abeygunawardena and Alexander, 2001). Currently 200,000 AIs are performed annually (The National Livestock Breeding Policy, 2010). Continuous upgrading of existing dairy cattle through National Artificial Insemination program has undoubtedly contributed to the increase in milk production in the country. The national AI program for dairy cattle is carried out according to the national breeding policy. Accordingly, the type of semen to be used in a particular farm depends on the management system, the agroclimatic zone and the breed of the cow. The implementation of such a comprehensive breeding program requires the maintenance of different breeds of semen donor bulls for semen production.

The Central Artificial Insemination Station (CAIS) in Kundasale, Sri Lanka is responsible for processing and distributing DF semen for artificial insemination of cattle and buffaloes throughout the country. Different dairy breeds of semen donor bulls such as Friesian, Jersey, Sahiwal and their crosses are maintained at CAIS. Most semen donor bulls have been imported to the country at a young age and subsequently were recruited as semen donors after criteria for DF semen were met. Artificial inseminations have also been carried out in recent years using sex-sorted semen (Chang et al., 2017) on a trial basis through the CAIS.

Since CAIS has been the key institution for producing and distributing DF semen for national AI program, it has to validate the semen characteristics of the donors and assure the minimum requirements stipulated for good quality DF semen. The success rate of the AI field program is not only depending on the quality of semen but, handling of semen, $\mathrm{AI}$ technique and timely insemination of a cow. However, the feedback on the success rate from the field is of vital importance for CAIS, especially because none of the imported stud bulls have been progeny tested.
It has been shown that though the routine semen characteristics (volume, concentration, and motility) are good indicators to determine the quality of the semen, these parameters are poorly correlated with the fertility of the bull (RodriguezMartinez, 2006). However, the computer-assisted sperm analysis (CASA) gives an array of information on individual spermatozoon motility which correlates with fertility (Amann and Waberski, 2014; Kathiravan et al., 2011). Several indirect tests can be used to assess the fertilization capacity of ejaculated spermatozoa. Hypo-osmotic sperm swelling (HOS) is one of those tests which is used to assess the functional integrity of the sperm cell membrane (Agarwal et al., 2016). An intact and functionally active sperm cell membrane is essential for the fertilization process of the oocyte. Changes in cell membrane integrity of spermatozoa could occur during the freezing and thawing process. Spermatozoa with functional cell membranes will swell in the hypoosmotic medium allowing water transport across the membrane. This phenomenon indicates plasma membrane integrity and functional activity. Hence, the percentage HOS positive sperm in a fresh or frozen-thawed semen sample could be used to reflect the number of functional spermatozoa in a semen sample. Therefore, the present study was conducted to investigate the semen characteristics, to estimate the percentage of HOS positive spermatozoa in fresh and postthawed semen samples and to evaluate the field performance of these semen donors in the four selected provinces. It was also aimed to explore the effect of HOS positive sperms in frozenthawed semen on fertility.

\section{METHODOLOGY}

\section{Experimental animals and their management}

All the semen donor bulls $(n=21)$ belong to Friesian $(n=7)$, Jersey $(n=10)$, Friesian-Sahiwal crossbred $(\mathrm{n}=3)$ and Jersey-Sahiwal crossbred (n $=1$ ) genotypes in CAIS were included in the study. The ages of the bulls ranged from 3-12 years. Bulls were fed with $50 \mathrm{Kg}$ of chopped green fodder, $4 \mathrm{Kg}$ of concentrate mix and $100 \mathrm{~g}$ mineral mixture per day, and allowed for free access to water. All the bulls were individually housed with $2.5 \times 2.5 \mathrm{~m}$ sheds with a free runner. Two hours of physical exercise were given daily in the designated stud bull exercise area. Animals were vaccinated annually for HS and FMD and regularly screened for Trichomoniasis, Brucellosis, and Leptospirosis, and also treated for external and internal parasites as necessary. 


\section{Evaluation of semen characteristics}

During the two-year study period semen characteristics (volume, concentration, and motility) of all the bulls were recorded. Semen was collected in the morning on Mondays and Thursdays every week where two ejaculates of ten minutes apart were done using an artificial vagina. The volume $(\mathrm{ml})$ of ejaculate was recorded from the calibrated semen collection tube. Sperm concentration (millions $/ \mathrm{ml}$ ) of pooled ejaculate was measured by spectrophotometer (IVM, France). The percentage of sperm motility was assessed using diluted (1:1) semen under the phase-contrast microscope (10x and 20x).

\section{Hypo-osmotic swelling test (HOS)}

The HOS test was performed as described by (Jeyendran et al., 1984). Accordingly, $50 \mu \mathrm{l}$ of undiluted semen was added to $1 \mathrm{ml}$ of $100 \mathrm{mmol}$ solutions, gently mixed and incubated for 30 minutes. A drop of the incubated suspension was placed on a clean glass slide and covered with a coverslip before examining under $20 \mathrm{x}$ and $40 \mathrm{x}$ magnification of the microscope. The test conditions (osmolarity, temperature, and duration of incubation) were optimized prior to the testing of samples. The percentage of HOS positive sperm in the sample was obtained by counting at least 200 sperm cells. The HOS test for fresh semen was performed using two independent samples from each bull during the study period. The HOS test was conducted for representative samples from all the batches of semen dispatched to the provinces selected for the evaluation of field performances.

\section{Evaluation of field performance of stud bulls}

Stud bull performance was assessed using pregnancy rates for which the number of AIs performed and confirmed pregnancies for respective bulls were recorded from selected veterinary ranges representing four Provinces, namely Central, Northern, North Western, and Uva for 2010 and 2011 calendar years. Veterinary ranges were purposively selected based on the number of AIs performed in the range. Pregnancy rates for individual bull and for different genotypes (breeds or crosses) of semen donors were calculated.

\section{Statistical Analysis}

Statistical analysis was performed only for the semen data collected from Jersey, Friesian and Friesian x Sahiwal crossbred bulls using Minitab statistical package version. Data of single semen donor bull (Jersey-Sahiwal crossbred) was not included for statistical analysis. However, the descriptive data were presented where appropriate. The pregnancy rate by different bulls in each province was presented as a percentage. Percentage of HOS positive sperm in fresh and post thawed semen samples in different bulls were compared using one-way ANOVA Correlation analysis was performed to study the relationship between pregnancy rate and percentage of motile sperm in fresh and frozen semen in individual bull.

\section{RESULTS}

\section{Semen volume}

The mean ejaculatory volumes $(\mathrm{ml})$ of Jersey, Friesian and Friesian x Sahiwal were $5.32 \pm 0.1$, $7.18 \pm 0.1$ and $5.79 \pm 0.8$, respectively, and the volumes were significantly $(\mathrm{P}<0.01)$ different among breeds. Semen volume within Jersey and Friesian breeds also showed significant differences. Two bulls (276 and 277) in Jersey breed ejaculated significantly lower semen volumes than the other bulls. Only one bull (440) among Friesians had significantly low semen volumes. The highest and the lowest recorded volumes $(\mathrm{ml})$ of ejaculates were $9.36 \pm 0.3$ and 3.3 \pm 0.2 for both Friesian and Jersey bulls.

\section{Sperm motility}

The average percentage of motility of sperm in fresh semen was above $70 \%$ in all bulls. There was no significant difference in semen motility among genotypes and different bulls. The average motility in post-thawed semen samples of all bulls ranged between $50-60 \%$ and no significant difference $(p>0.05)$ was observed among and within genotypes. However, the fresh semen of all bulls had significantly higher $(\mathrm{p}<0.01)$ motility than post thawed semen.

\section{Sperm concentration}

Mean sperm concentrations in fresh semen showed a significant $(\mathrm{p}<0.01)$ difference among and within different genotypes. Sperm concentration of Jersey breed $\left(1026 \pm 22 \times 10^{6}\right.$ per $\mathrm{ml})$ was significantly $(\mathrm{p}<0.01)$ different from Friesian and Friesian $\mathrm{x}$ Sahiwal breeds. The highest $\left(1630 \pm 77 \times 10^{6}\right.$ per $\left.\mathrm{ml}\right)$ and the lowest (406 $\pm 25 \times 10^{6}$ per ml) sperm concentrations in fresh semen were produced by a Jersey (No.270) 
and a Friesian x Sahiwal (No. 986) bulls, respectively. The mean sperm concentration of Sahiwal and Jersey x Sahiwal bulls were $837 \pm 59$ and $705 \pm 30 \times 10^{6}$ per ml, respectively.

\section{HOS test performance}

Percentages of HOS positive sperms in fresh semen for individual bulls of different breeds were the highest (85\%) in Jersey (No.274) and the lowest (65\%) in Friesian (431) bulls. In postthawed semen, the highest percentages of HOS positive sperms were found in the same Jersey bull and the lowest (63\%) was found in Friesian bull No. 439. The average percentage of HOS positive sperms in fresh semen was $81.1 \pm 1.9$ in Jersey and it was $76.8 \pm 4.3$ in Friesian. The values were not significantly ( $p>0.05)$ different between the two breeds. In post-thawed semen, the values were $74.6 \pm 2.0$ in Jersey and $69.5 \pm 3.8$ in Friesian $(\mathrm{p}>0.05)$. There was a positive correlation between the percentage of HOS positive sperms in fresh and post-thawed frozen semen ( $r=0.77$ ). Results of the t-test revealed that the percentage of HOS positive sperms was significantly lower $(\mathrm{p}<0.05)$ in post-thawed frozen semen $(72.7 \pm 1.9)$ than in fresh semen $(79.5 \pm 1.9)$.

\section{Pregnancy rate}

A total of 49255 AIs was performed in four provinces during the study period whereas the calving reported were 18962 resulting an overall pregnancy rate of $28.2 \%$ (Table 1 ). The highest number of AIs have been done in Uva Province and the pregnancy rate of the province was 27.3\%. Northern Province recorded the lowest number of AIs during the study period. However, the pregnancy rate in Northern Province was over $50 \%$. The predominant type of semen used in all provinces was Jersey and this was followed by Friesian, Jersey x Sahiwal, Friesian x Sahiwal and Sahiwal. The pregnancy rates of Jersey bulls were found to be $22.4 \%, 52.1 \%, 48.5 \%$ and $26.8 \%$ for
Central., Northern, North-Western, and Uva provinces, respectively, while it was $22.6 \%, 79.1$ $\%, 42.0 \%$ and $47.0 \%$ for Friesian bulls, respectively in the same provinces (Table 1).

\section{DISCUSSION}

\section{Semen volume}

Results of the present study revealed a significant variation in semen volumes of individual bulls as well as among different genotypes. Previous studies also reported a significant breed difference in the volume of semen of pure and crossbred bulls (Kumar et al., 2015) and also among individual bulls (Nasrin et al. 2008). The mean ejaculate volume of bulls in the present study was found to be higher than the values of $4.05 \pm 0.03 \mathrm{ml}$ for Friesian and $2.92 \pm 0.03 \mathrm{ml}$ for Jersey reported by Fiaz et al., (2010). This difference could be due to managerial and environmental effects. Ejaculate volumes of Friesians and Jersey bulls were affected by the season of the year hence seasonal stress reduced the ejaculate volumes (Fiaz et al., 2010). The ejaculatory volume of stud bulls is an important parameter because, the higher the ejaculatory volume, the higher the number of doses of frozen semen produced from stud bulls.

\section{Sperm motility}

Sperm motility in fresh (70\%-80\%) and postthawed frozen semen (50\%-60\%) were above the accepted standard and there was no significant variation in sperm motility in individual semen donor bulls. This observation tallies well with the previous reports which ranged between $50 \%$ and 80\% (Kumar et al., 2015; Vasan, 2011). In addition, the semen concentrations of bulls in this study were in agreement with the previous findings.

Table 1: Pregnancy rates of the semen donor bulls managed at the Central Artificial Insemination Station.

\begin{tabular}{lcccccccc}
\hline & \multicolumn{1}{c}{ Province } \\
\cline { 2 - 10 } Breed & \multicolumn{2}{c}{ Central } & \multicolumn{2}{c}{ Northern } & \multicolumn{2}{c}{ North Western } & \multicolumn{2}{c}{ Uva } \\
\cline { 2 - 10 } & $\begin{array}{c}\text { Total } \\
\text { AIs }\end{array}$ & $\begin{array}{c}\text { Pregnancy } \\
\text { Rate } \%\end{array}$ & $\begin{array}{c}\text { Total } \\
\text { AIs }\end{array}$ & $\begin{array}{c}\text { Pregnancy } \\
\text { Rate } \%\end{array}$ & $\begin{array}{c}\text { Total } \\
\text { AIs }\end{array}$ & $\begin{array}{c}\text { Pregnancy } \\
\text { Rate } \%\end{array}$ & $\begin{array}{c}\text { Total } \\
\text { AIs }\end{array}$ & $\begin{array}{c}\text { Pregnancy } \\
\text { Rate \% }\end{array}$ \\
\hline Jersey & 4694 & 22.4 & 1722 & 52.1 & 9097 & 48.5 & 14259 & 26.8 \\
Friesian & 2634 & 22.6 & 441 & 79.1 & 1385 & 42.0 & 994 & 47.0 \\
Overall & 7328 & 22.5 & 2163 & 57.6 & 10482 & 47.6 & 15253 & 28.2 \\
\hline
\end{tabular}


Nasrin et al., (2008) also has reported that the sperm motility varied in individual bulls. The variation among individuals could be due to the differences in their genotype and location related environmental factors.

The best evaluation of fresh and frozen semen samples could be achieved by measuring the sperm motility before processing and also taking into consideration the percentage of dead and morphologically abnormal cells (Wael et al., 2018; Vasan, 2011). However, there was no regular testing done to detect the percentage of abnormal sperms present in individual bulls in CAIS. Previous studies have shown that pregnancy rate correlates with all measures of motility including dead or abnormal sperm content in semen (Vasan, 2011). However, the post thawing sperm motility of $50 \%$, which was often stipulated for approval of the semen after freezing, did not seem to be the optimal choice (Stålhammar et al.,1994). Post thawing motility of all semen donors at CAIS was above this threshold. Evaluation of the fertility of semen donors should be based on direct recording and evaluation of non-return rates. The motility parameters had been used to test the fertility of bulls in the field (Vasan, 2011).

\section{Sperm concentration}

This study revealed that sperm concentration significantly varied among and within different genotypes. A Jersey stud bull produced the highest concentration of semen, and the lowest sperm concentration was recorded by a Friesian $\mathrm{x}$ Sahiwal bull. Nasrin et al., (2008), Hafez (1993) and also reported the similar findings in their respective studies. Nasrin et al., (2008) further described that sperm concentration was positively correlated with non-return rates (However, Foote and Kaproth (1997) indicated that total sperm numbers per straw could be reduced to $10 \times 10^{6}$ under good management and semen handling conditions, without reduction of non-return rates at 59 days). Sperm concentration below 500 million/ml was not used for processing DF semen and only a few ejaculates were discarded due to poor sperm concentration in CAIS during the study period.

\section{HOS positive sperm percentage and pregnancy rate}

HOS of the sperm tail is used to assess the spermatozoa cell membrane integrity (Ramu and Jeyendran, 2013). Previous studies revealed that there is positive correlation between HOS positive sperm and bull fertility (Samardzija et al., 2008). The percentage of HOS positive sperms in the fresh semen of this study was higher than that of frozen semen. This indicates that semen processing causes some damage to the cell membrane. Januskauskas and Zilinskas (2002) had reported that processes of semen dilution, chilling, freezing, storage and thawing can reduce the viability of sperms. Percentage of HOS positive sperms in a semen sample found to be changed according to the bull (Prasad et al.,1999), season (Kale et al., 2000), semen traits (Prasad et al., 1999) and fertility (Vasan, 2011).

Use of large number of frozen semen samples from bulls with a wide range of fertilities were recommended to find out the relationship between semen evaluation methods and fertility, over the use of the limited range of non-return data from a small group of regular bulls (Vasan, 2011). Lodhi et al., (2008) suggested routine testing of the HOS test of semen samples as an indirect method of evaluating fertility in vivo. In addition to the HOS test, estimation of potential fertility of bulls could also be achieved by thermal stress test and modified cervical mucus penetration test, in combination with routine dermatological tests (Bacinoglu et al., 2008). Correa et al., (1997) found a high correlation coefficient between fertility and sperm characteristics in frozen-thawed semen such as motility $(\mathrm{r}=0.53 ; \mathrm{p}<0.01)$, normal morphology $(\mathrm{r}$ $=0.59 ; \mathrm{p}<0.01)$ and swollen spermatozoa $(\mathrm{r}=$ $0.57 ; \mathrm{p}<0.01$ ). The maximum sperm swelling was found as an indication of high fertility during the same study. However, Martins et al., (2011) found that even though there were significant differences in physical and morphological aspects of semen between highly fertile and poorly fertile bulls, no difference was found in the mean percentage of reactive sperm in HOS test.

\section{Pregnancy rate}

The overall pregnancy rate reported in the study was $28.2 \%$ (Table 1 ), and the most predominant semen used in all 4 provinces was Jersey. This is primarily due to the recommendation of Jersey semen for intensive and semi-intensive systems of cattle management in all provinces in Sri Lanka. The majority of the farmers in provinces where this study was conducted managed their cows semi-intensively and hence used Jersey semen. Apart from the recommendation, the crossbred offspring of Jersey were preferred by farmers owing to their small body size, tolerance to heat and increase butterfat. These advantages make the Jersey crosses easy and economical to manage over Friesian counterparts. 
The Central province recorded the highest usage of Friesian semen. A considerable part of the province has favourable environmental conditions for rearing Friesian. Therefore, most farmers in this province, particularly those in the estate sector preferred Friesian cows. Owing to continuous upgrading, the cows in the area possess high level of Friesian genotype. Hence, farmers prefer inseminating their cows with Friesian semen. The highest number of AI during the study period was performed in Uva province and the overall PR recorded for inseminated cows in the province was $27.3 \%$. Ninety-three percent of recorded AIs in this province were done using Jersey semen and Friesian semen was used sparingly. The number of AIs performed in Central Province was nearly half of AIs recorded in the Uva province. Overall PR of Central province was less than Uva Province. In Central Province, PR for Jersey (22.4\%) and Friesian (22.6\%) semen were quite similar. In contrast, PR of Friesian semen $(47 \%)$ in Uva Province was much higher than that of Jersey semen (26.8\%). The PR could be influenced by many factors such as the timing of $\mathrm{AI}$ and experience of the AI technician (Paul et al., 2011) Causes for the poor performance of Jersey semen in the Uva province is difficult to explain based on the results of this study. The performance of both semen types (Jersey and Friesian) in North Western and Central provinces were remarkably low.

Pregnancy rates of Northern and Central Provinces were significantly different from overall PR. The difference in pregnancy rates between the semen from two breeds (Jersey and Friesian) was not significant $(p>0.05)$. This indicates that all the bulls in the study were equally fertile. However, Abeygunawardena and Alexander (2001) reported that the overall percentage of calving due to $\mathrm{AI}$ or the success rate for inseminations in the country was low (6.3\%). Accurate feedback results for each insemination performed at the field level should reach the semen collection centre to determine the fertility levels of the donor bulls. However, managing donor bulls, collection, and processing of semen, maintenance

\section{REFERENCES}

Abeygunawardena, H. and Alexander, P.A.B.D. (2001). Artificial insemination of cattle in Sri Lanka; Status, performance and problems. In: radioimmunoassay and related techniques to improve artificial insemination programs for cattle reared under tropical and subtropical conditions. Proceeding of a final research coordination meeting organized by the Joint and transport of semen, semen handling and AI service monitoring are the key components of any efficient AI Programme.

\section{CONCLUSIONS}

Semen traits of fresh and post-thawed frozen semen of donor bulls maintained at CAIS were within the accepted range. Friesian bulls produced the highest volume while the Jersey bulls had the highest sperm concentration in fresh semen. The motility of spermatozoa in fresh and post-thawed frozen semen was not varying among the individual bulls and among the breeds. The motility of spermatozoa in fresh semen was significantly higher $(\mathrm{p}<0.01)$ than that in postthawed frozen semen. Pregnancy rates within and among different genotypes were not significantly different. However, a significant difference $(\mathrm{p}<0.01)$ in pregnancy rate was found among different provinces. The higher percentage of hypo-osmotic swelling positive spermatozoa in both fresh and post-thawed frozen semen indicated that all bulls studied at CAIS were highly fertile. However, pregnancy rate of those bulls was found to be low (overall pregnancy rate of $28.2 \%$ ) compared to the acceptable standards of $50 \%$ (Taponen, 2009). The low pregnancy rate experienced at field level could be associated with some other factors such as improper maintenance and handling of semen, incorrect technique in the insemination procedure, poor recording, adverse climatic factors and poor oestrus detection at field level.

\section{ACKNOWLEDGEMENTS}

The authors would like to acknowledge the guidance provided by the MVSc Program (Theriogenology) of the Faculty of the Veterinary Medicine and Animal Science and also thank the staff of the Central Artificial Insemination Center, Kundasale.

FAO/IAEA. Division of Nuclear Techniques in Food and Agriculture held in Uppsala, Sweden.

Agarwal., A., Gupta, S. and Sharma, R. (2016). Hypoosmotic Swelling Test (HOS). Andrological Evaluation of Male Infertility. Springer, Cham. https://doi.org/10.1007/978-3-319-26797-5_12 (Accessed on 23/07/2021)

Amann, R.P. and Waberski, D. (2014). Computerassisted sperm analysis (CASA): capabilities and 
potential developments. Theriogenology. 81(1), 517.e1-3.

Alexander, P.A.B.D., Abeygunawardena, H., Perera, B.M.A.O. andAbeygunawardena, I.S. (1998). Reproductive Performance and Factors Affecting the Success Rate of Artificial Insemination of Cattle in Up-country Multiplier Farms of Sri Lanka. Tropical Agricultural Research. 10, 356-371

Bacinoglu, S., Tas, M., Cirit, U., Ozadas, O.B. and Ak, K. (2008). The potential fertility estimation capacity of the hypoosmotic swelling test, the thermal stress test and a modified cervical mucus penetration test in the bovine. Animal. Reproduction Science. 104(1), 38-46.

Chang, L.B., Chou, C.J., Jia,S.S., Po, A.T., Shi, X.G., Shao,Y.P. and Shinn C.W. (2017). Artificial insemination of Holstein heifers with sex-sorted semen during the hot season in a subtropical region. Trop Anim Health Prod. 49, 1157-1162.

Correa, J.R., Pace, M.M. and Zavos, P.M. (1997). Relationships among frozen-thawed sperm characteristics assessed via the routine semen analysis, sperm functional tests and fertility of bulls in an artificial insemination program. Theriogenology. 48(5), 721-731.

Fiaz, M., Usmani, R.H., Abdullah, M. and Ahmad, T. (2010). Evaluation of semen quality of Holstein Friesian and Jersey bulls maintained under subtropical environment. Pakistan Veterinary Journal. 30(2), 75-78.

Foote R.H. and Kaproth, M.T. (1997). Sperm numbers inseminated in dairy cattle and nonreturn rates revisited. Journal of Dairy Science. 80(11), 3072-3076

Hafez, E.S.E. (1993). Artificial Insemination. In: E.S.E. Hafez (editor). Reproduction in farm animals. Febiger, Philadelphia, USA, pp. 424-439.

Jainudeen, M.R. (1968). The use of imported frozen semen in routine insemination of dairy cattle in Ceylon. Ceylon Veterinary Journal. 16(12), 7-10.

Januskauskas, A. and Zilinskas, H. (2002). Bull semen evaluation post-thaw and relation of semen characteristics to bull's fertility. Vet. Med. Zoot.17(39).

Jeganathan, P. (1955). A review of the progress of artificial insemination of cattle in Ceylon. Ceylon Veterinary Journal. 3(1-2), 6-31.
Jeyendran, R.S., Van der Ven, H.H., Perez-Pelaez, M., Crabo, B.G. and Zanevald, L.J.D. (1984). Development of an assay to assess the functional integrity of the human sperm membrane and its relationship to other semen characteristics. Journal of Reproduction and Fertility. 70, 219-228.

Kale, M.M., Manik, R.S. and Tomer, O.S. (2000). Invitro assessment of crossbred buck fertility. Indian Journal of Animal Science. 70, 25-29.

Kathiravan, P., Kalatharan, J., Karthikeya, G., Rengarajan, K. andKadirvel, G. (2011). Objective sperm motion analysis to assess dairy bull fertility using computer-aided system--a review. ReprodDomest Anim. 46(1),165-72.

Kumar, U., Gawande, A.P., Sahatpure, S.K., Patil, M.S., Lakde, C.K., Bonde, S.W., Borkar, P.L, Poharkar, A.J. andRamteke, B.R. (2015). Assessment of semen quality in pure and crossbred Jersey bulls, Veterinary World 8(10), 1266-1272.

Lodhi, L.A., Zubair, M., Qureshi, Z.I., Ahmad, I. and Jamil, H. (2008). Correlation between hypoosmotic swelling test and various conventional semen evaluation parameters in fresh Nili-Ravi buffalo and Sahiwal cow bull semen. Pakistan Veterinary Journal. 28(4), 186-188.

Mahamooth, T.M.Z. (1955). Development of artificial method of breeding livestock in Ceylon. Ceylon Veterinary Journal. 3(1-2), 2-5.

Martins, L.F., Pinho, R.O., Siqueira, J.B., Guimaraes, S.E.F., Neto, T.M. and Guimaraes, J.D. (2011). Correlation between hypo-osmotic swelling test and breeding soundness evaluation of adult Nelore bulls. Italian Journal of Animal Science. $10(3), 41-46$.

Ministry of Livestock and Rural Community Development (2010). The National Livestock Breeding Policy-Guidelines and Strategies for Sri Lanka. ISBN NO: 978-955-0355-01-3

Nasrin, S., Amin, M.R. and Alam, M.K. (2008). Evaluation of semen and non-return rate of bulls in artificial insemination (AI) center. Bangladesh Journal of Animal Science. 37(2), 1-7.

Paul, A.K., Alam M.G. S. and Shamsuddin, M. (2011) Factors that limit first service pregnancy rate in cows at char management of Bangladesh. Parity. $215,45-5$.

Prasad, J.K., Kumar, S. Mohan, G., Shanker, U. and Agarwal., S.K. (1999). Hypo-osmotic swelling test 
(HOST) and its response in fresh and freezethawed semen. Indian Journal of Animal Science. 69, 766-769.

Ramu S. andJeyendran R.S. (2013). The Hypoosmotic Swelling Test for Evaluation of Sperm Membrane Integrity. In: Carrell D., Aston K. (eds) Spermatogenesis. Methods in Molecular Biology (Methods and Protocols), Humana Press, Totowa, NJ,pp. 21-25.

Rodriguez-Martinez, H. (2006). Can we increase the estimative value of semen assessment? Reproduction in Domestic Animals. 41(2), 2-10.

Samardzija, M., Dobranic, T., Kruslin, S., Cergolj, M., Karadjole, M., Prvanovic, N. and Grizelj, J. (2008). The use of the hypoosmotic swelling test and supravital staining in evaluation of sperm quality in boars. The Journal VeterinarskiArhiv. 78(4), 279-287.
Stålhammar, E.M., Janson, L. andPhilipsson, J. (1994). The impact of sperm motility on nonreturn rate in preselected dairy bulls. Reproduction Nutrition Development 34(1), $37-$ 45.

Taponen, J. (2009). Fixed-time artificial insemination in beef cattle. Acta Vet Scand 51, 48.

Vasan, S.S. (2011). Semen analysis and sperm function tests: How much to test? Indian J Urol. 27(1), 41-48.

Wael, A. K., Mostafa, A. E., Alaa E.B., Mahmoud Z., Hassan A.E. and Omnia, M.E. (2018). Evaluation of bull spermatozoa during and after cryopreservation: Structural and ultrastructural insights, International Journal of Veterinary Science and Medicine. 6, S49-S56. 